\title{
Risk Perception Analysis with FAHP in Turkish Brand Patented Automobile Production
}

\author{
Buket Karatop \\ Istanbul University, Cerrahpaşa Technical Sciences Vocational School, Istanbul, Turkey \\ Cemalettin Kubat \\ Sakarya University, Faculty of Engineering, Sakarya, Turkey \\ Ibrahim Yildiz \\ Istanbul University, Cerrahpaşa Technical Sciences Vocational School, Istanbul, Turkey
}

\begin{abstract}
Detailed analysis of the products that are accepted as status indicators in the society must be done before the presentation to the market. Cars are also considered as status indicators in society. Performing perception analysis before the presentation to the market will provide many benefits. For products that have not been produced, perception analysis also reveals the expectation of the customer. It can be said that the individual perceives the risk about the product if perception of potential customers is creating a negative impact on the buying trends. Customer's perception of risk affects the purchasing decision of the individual in terms of financial, psychological, physical, functional, social and time criteria. Risk perception encountered in real life in all areas is a multi-criteria concept with uncertainty. In the study, fuzzy logic method which gives successful results in uncertainties was used together with AHP method which is commonly used in multi-criteria decision making (MCDM) problems. The article used the risk perception in Turkish Brand Patented Automobile (TBPA) production with fuzzy analytic hierarchical process (FAHP) method. The potential customer's risk perception and wishes and expectations are presented.
\end{abstract}

Keywords: Perception, MCDM, Fuzzy Logic, TBPA

DOI: $10.7176 / \mathrm{JSTR} / 5-3-22$

\section{Türk Marka Patentli Otomobil Üretiminde FAHP ile Risk Algısı Analizi}

\begin{abstract}
Özet
Toplumda statü göstergesi olarak kabul edilen ürünlerin pazara sunumundan önce çeşitli analizlerin detaylı yapılması gerekir. Otomobil de toplumda statü göstergesi olarak kabul edilen ürünlerdendir. Pazara sunumu öncesinde alg1 analizinin yapılması pek çok fayda sağlayacaktır. Üretimi gerçekleşmemiş bir ürün için alg1 analizleri aynı zamanda müşterinin beklentisini de ortaya koymaktadır. Bu algı potansiyel müşterinin satın alma eğiliminde olumsuz etkiler oluşturuyor ise bireyin ürün hakkında risk algıladığından bahsedilebilir. Risk algısı finansal, psikolojik, fiziksel, fonksiyonel, sosyal ve zaman kriterleri açısından bireyin satın alma kararını etkiler. Gerçek hayatta her alanda karşılaşılan risk algısı belirsizlik özelliği taşıyan çok kriterli bir kavramdır. Çalışmada çok kriterli karar verme (ÇKKV) problemlerinde sık kullanılan AHP yöntemi ile belirsizliklerde başarılı sonuçlar veren bulanık mantık yöntemi bir arada kullanılmıştır. Makale Türk Marka Patentli Otomobil (TMPO) üretiminde risk algısı bulanık analitik hiyerarşik proses yöntemi (BAHP) ile gerçekleştirilmiştir. Potansiyel müşterinin risk algısı ile istek ve beklentileri sunulmuştur.
\end{abstract}

Anahtar Kelimeler: Alg1, ÇKKV, bulanık mantık, BAHP, TMPO

201 | P a g e

www.iiste.org 


\section{Giriş (Introduction)}

Dünya ekonomisinin bel kemiğini oluşturacak kadar büyük bir üretim hacmine sahip olan otomotiv sektörü, ekonomi ve sanayinin gelişmesine lokomotif görevi görmekle birlikte aynı zamanda teknolojinin ve müșteri vizyonunun gelişmesinde de önemli rol oynamaktadır. $\mathrm{Bu}$ ve benzer nedenlerden dolayı tüm gelişmiş ülkelerin odaklandığı bir sektördür (Karatop, 2015). Devletler ekonomilerini güçlü tutmak ve gücün devamlılığını sürdürmek için otomotiv sektörünü desteklemekte, rekabet unsurları da artmaktadır. Günümüz rekabet koşulları içerisinde yoğun mesaj bombardımanına maruz kalan bireyin ürün tercihini etkilemede algı önemli bir rol oynamaktadır.

Özer (2012) algının "kişilerin çevreleriyle ilgili uyarıyı duyma, organize etme, anlama ve değerleme süreci olarak değerlendirilmekte" olduğunu ve aslında algının, "duyu organlarından gelen verilerin (bilgi, uyarı) organize edilmesi ve onlara anlam verilmesi ile ilgili süreci ifade ettiğini” bildirmektedir. Uyarıcının ve algılayanın özellikleriyle etkileşimi algıllama işlevini oluşturur (Cüceloğlu, 2007). Algılama dinamik bir süreç olmakla birlikte her zaman doğru bilgi ile şekillenmeyebilir. Doğru bilgi ile şekillenmesini sağlamak aslında iş etiği açısından da önemlidir ve ürün yada hizmeti sunan açısından müş̧eriye güven telkin eder.

Günümüzde bir yandan ürün ve hizmet çeşitliliğinin, diğer yandan tüketici istek ve beklentilerinin artmas1 tüketiciyi rahatsız eden unsurların da -risk algısı da bu unsurlardan biridir- artmasına neden olmaktadır. (Schiffman ve Kanuk, 2000'dan aktaran Demir ve Kozak, 2013). Risk algısı tüketicinin davranışlarını etkileyeceği için özellikle pazara yeni sunulan ürünlerde algı analizlerinin bilimsel yöntemlerle yapılması önem kazanmaktadır.

Ronnie vd., (2006) göre algılama, "belirsizliği düşük olan, yüksek fayda içeren, içeriği dolu bilgileri dış dünyadan sağlama yöntemlerini geliştirme ve bunların kontrolünü sağlayan ve bu duruma uyan konseptler geliştirme yöntemi olarak bilinmektedir. Burada geçerli olan konseptler, gerekli verileri sağlama sürecinin bir sonucu olarak yapay zekâ sisteminin içsel bir parçasıdır. Bu bakış açısıyla hareket ettiğimizde algılama yönetiminin içeriğini belirleyebiliriz." Algıda riskin en önemli unsurlarından bir olan belirsizlik ile satın alma kararı arasında yakın bir ilgi mevcuttur.

Makalenin amacı Türk marka patentli otomobil üretimi için potansiyel müşterilerin (tüketicinin) ürün hakkındaki risk algılarını ortaya koyarak üretici firmalara üretim stratejileri için ön bilgi sunmaktır.

\section{Algı Kavramı ve Risk Algısı (Perception Concept and Risk Perception)}

Literatürde birçok algı tanımı bulunmaktadır. Doğar’a göre (2016), Algı kavramı, “modern dünyanın özellikle medya etkisi nedeniyle ön plana çıkardığı kavramlardan birisidir. Kısa ve basitçe, hedef kitlenin istenilen doğrultuda etkilenmesi ve yönlendirilmesi şeklinde tanımlanabilir. Maksat, hedef kitlenin belirli bir konu, amaç, ilke vb. inandırılmasıdır. Bu yönüyle algı, oluşturulacak temaları, yönetimi ve araçları ile başlı başına bir süreçtir”. Algı, canlıların dünyayı anlamlı bir şekilde deneyimlemek için duyumları yorumladığı ve düzenlediği bir süreçtir. Başka bir ifade ile bir durum veya uyaranla karşı karşıya kalan kişinin uyaranları önceki deneyimlere dayanarak kendisi için anlamlı bir şeye çevirmesidir. Bu açıdan bireylerin yorumladığı veya algıladığı şey gerçeklikten farklılık gösterebilir (Pickens, 2005).

Algılama bir süreç olarak değerlendirildiğinde; kişilerin sahip oldukları değer yargıları, amaç ve hedefleri, ihtiyaçları, içinde yetiştikleri kültürel ortam, bilgileri, hisleri, geçmişteki tecrübeleri ve hatta biyolojik ve fiziksel özellikleri gibi birçok etmen tarafindan bu süreç etkilenmektedir. Bunun sonucu olarak da aynı olay farklı kişiler tarafindan değişik şekillerde algılanmaktadır. (Eren, 2001'den aktaran Özsalmanlı ve Pank, 2013). Algılama sürecinde, bireyin çevresinde algının oluşumuna katkı sağlayan birçok etmen bulunmaktadır. Aynı zamanda bireyin içinde bulunduğu doğal alan ile geçmişten gelen sosyo-kültürel ortam adı verilen yapay alan söz konusudur (Kotler, 2001'den aktaran Erişti vd., 2013). Bireyin algılaması bu etmenler ve alanların etkisinde gerçekleşmektedir.

Algılama sürecinde hedef kitleye pazarlama iletişim unsurlarının ve dolayısıyla istenen bilgilerin ulaşmasına maruz kalma (exposure) denilmektedir (Koç, 2015).

Algılama sürecindeki en önemli etmen olan bireyler, algılanan aynı kavrama farklı algısal tepkiler verebilmektedir. Algılama sürecindeki bireylerin dikkat, algısal değişkenler ve algısal kalıcılıktaki seçiciliği bu sonucu doğurmaktadır (Kotler, 2001'den aktaran Erişti ve ark., 2013). Bireyin inanç ve tutumlarına uygun olmayan duyumlar algı sürecinden geçerken algısal savunma bu duyumlara karşı bir engel oluşturur. Bu duruma seçici algl (selective perception) denir. Seçici algı, bireyin inanç, tutum ve deneyimlerine dayanarak gelen uyaranları yorumlayıp sınırlaması ile ortaya çıkar (Pickens, 2005). Bazı özelliklerine göre dikkatimizi çeken dış dünyadaki uyarıcılar hemen seçilir ve algılanırlar. Seçip algılanan uyarıcının büyüklüğü, değişkenliği, şiddeti gibi özellikleri

202 | P a g e

www.iiste.org 
seçiciliğini sağlamaktadır. Duyu organı uzun süre maruz kaldığı uyarıcıya uyum sağlar ve değişiklik olduğunda hemen fark eder. Uyarıcıda parlak renkler, yüksek ses, kuvvetli koku gibi büyüklüğü ve şiddeti yüksek olan özellikler de dikkat çekmekte algıda seçiciliği tetiklemektedir (Cüceloğlu, 1999).

Uyarıcıdan etkilenen bireyin içinde bulunduğu durumu yorumlaması devreye girmektedir. Demir ve Kozak'a (2013) göre yorumlama "uyarıcıların yapısı, ortamı, netliği, kişinin yaşantısı ve deneyimi, gereksinim ve güdülerine göre" farkl1lık gösterebilmektedir.

Tüketicinin veya potansiyel müşterinin satın alma eğiliminin sonuçlarındaki negatiflik derecesi ve negatif sonuçların gerçekleşme olasıllı̆̆ "algılanan risk seviyesidir" (Koç, 2015). Bireyin risk algılaması, gerçek olay ve durumlardan hareketle kendi zihninde oluşturduğu bir çerçeveye göre oluşturmasıdır. Buna çerçeveleme (framing) denir. Sonuçta birey veya tüketici risk algısına göre risk derecelerini belirler ve buna uygun davranış biçimi, satın alma eğilimi belirler. Risk algılama ve kabullenme dereceleri kişiden kişiye farklılık göstermektedir. Bazılları risk almayı severken, bazıları ise riskten kaçınma noktasında hareket ederler. Örneğin; risk arayıcılar olarak tanımlanan yamaç paraşütü yapan tüketicilerin risk alma eğilimi daha yüksektir (Koç, 2015).

Risk algısı tüm disiplinlerde varlığından söz edilebilir ve pazarlama alanında ilk 1960 yıllarında Bauer'in çalışmalarında görülmektedir (Snoj vd., 2004'den aktaran Aktan 2013). Risk algısı, satın almadan önce anlaşılamayan, sadece tahmin edilebilen ancak kullanım esnasında olumsuz sonuçlara neden olabilecek ürüne ait unsurlardan oluşmaktadır (Aktan, 2013). Aktan (2013) literatürde risk algısının 6 boyutta ele alınabileceğini bildirmektedir. Bu 6 risk algısı üzerinden uygulama yapılmıştır.

Literatürde Kaplan ve ark. (1974) ve Stone ve ark (1993) tarafindan risk algısı altı boyutta incelenmiştir (Aktan, 2013; Demir, 2011)

$\checkmark \quad$ "Finansal Risk: Ürüne verilen paranın boşa gitmesi, ürünle ilgili olası maddi kayıpla ilgili risktir. Tüketicilerin bir ürünü satın aldıkları zaman kabullendikleri mali yükümlülükler finansal riske neden olmaktadır. Ürünün fiyatı arttıkça finansal riskin artması beklenir.

$\checkmark \quad$ Psikolojik Risk: Ürünün tüketicinin egosuna zarar vermesi riskidir. Tüketicinin özgüveniyle ilgili risktir. Sosyal risk, diğer insanların tüketiciyle ilgili olumsuz düşüncelerinden meydana gelen risk iken, psikolojik risk tüketicinin kendisinin ürünün sahibi olmaktan veya ürünü kullanmaktan memnun olmamasıly ilgili endişeleridir.

$\checkmark \quad$ Fiziksel Risk: Ürünün kullanımı esnasında kullanıcıya ve başkalarına zarar vermesi riskidir. Sağlık veya fiziksel durumla ilgili risktir. Bir ürünün kullanımı sırasında karşılaşılan tüm sağlık ve fiziksel durumla ilgili endişeler bu risk grubuna girer.

$\checkmark$ Fonksiyonel Risk: Ürünün istenilen performansı verememesi riskidir. Ürünün performansıyla ilgili risktir. Tüketicinin satın alım ile karşı karşıya iken üründen elde edeceği faydadan emin olmaması tüketicinin bir risk ile karşı karşıya olmasına neden olmaktadır. Ürün ilk defa satın alınıyorsa, ürün hakkında bilgi yoksa veya ürünün kullanımı uzmanlık gerektiriyorsa fonksiyonel riskin artması beklenir.

$\checkmark \quad$ Sosyal Risk: Ürünün sosyal çevrede kabul görmemesi ve kullanıcının imajını zedelemesi riskidir. Bir ürün veya markanın kullanılması durumunda diğer insanların tüketici hakkındaki olumsuz düşünmeleri riskidir.

$\checkmark$ Zaman Riski: Ürünün kötü olması durumunda, satın alma esnasında harcanan zamanın boşa gittiğinin düşünülmesidir. Yanlış ürünün tercih edilmesi nedeniyle maruz kalınan zaman kaybı riskidir.”

Fiziksel risk daha çok ürüne güvenme ile ilgilidir. Fiziksel güvenirlilik riski de denilebilir. Zaman riski ise yanlış ürün seçimi neticesinde oluşan risktir. Pazara girmemiş bir ürün için tüketicinin algısı, pazarda yer almış üründen daha önemli olduğu söylenebilir. Potansiyel müşterinin yeni ürün hakkındaki risk algılarını minimize eden stratejilerle ürün satışında verimli sonuçlar elde edilebilir.

\section{3. ÇKKV ve Bulanık Mantık (MCDM and Fuzzy Logic)}

Belirsizlik veya risk özelliği taşıyan gerçek hayat problemlerinde yapay zekâ tekniklerinin kullanılması, optimuma en yakın sonucun bulunmasını sağlamaktadır. Bulanık mantık ta yapay zekanın en önemli tekniklerinden biridir.

Gerçek hayat problemleri belirsiz şartlarda oluşmakta kesin olarak bilinmeyen olaylar hakkında karar vermek gerekmektedir (Öztemel 2009). Bulanık sistemler belirsiz ve özellikle de modeli matematiksel olarak kurulamayan sistemler için uygundur (Kubat, 2015). Klasik mantığın sıfır-bir, evet-hayır veya doğru-yanlış değişkenleri yerine gerçek hayat problemlerinin tanımlanmasında kullandığımız çok iyi-iyi-orta-kötü-çok kötü gibi kademeli değişkenler kullanan bulanık mantığın kurucusu Zadeh (Lütfü Askerzade)'dir. Bulanık kümeler, veri ve bilgiye

203 | P a g e

www.iiste.org 
sahip ancak istatistiksel olmayan belirsizliklerin temsili kullanılması için ilk olarak Zadeh (1965) tarafindan ortaya konulmuştur. Bilgi temelli sistemlere uygulanabilen bulanık mantık ile yaklaşık çıkarsama yapılabilmesi sağlamıştır. Bulanık küme teorisi ile düşünme ve uslama gibi insan bilişsel süreçleriyle birleşmiş belirsizlikleri içine alan matematiksel güç sağlamıştır (Kubat, 2012).

Stefanoiu ve ark. (2014) çok kriterli karar verme hem akademisyenler hem de iş hayatındaki uygulayıcılar için büyük ilgi alanı haline getiren gerçek hayt problemlerine ÇKKV yöntemlerinin çok sayıda başarılı uygulamasının olduğuna dikkat çekmektedir (Turskis ve ark, 2019). Turskis ve ark. (2019) aynı makalelerinde geçmiş çalışmalar dikkate alındığında araştırmacıların yaygın olarak analitik hiyerarşi prosesi (AHP) yöntemini kullandıklarından bahsetmektedir. Çoğu araştırmacının aynı fikirde olduğunu söylemek mümkündür.

AHP ilk olarak Saaty (1972) tarafindan geliştirilmiştir ve yöntemin detayları Saaty'nin (1977) "A scaling method for priorities in hierarchical structures" isimli makalede paylaşılmıştır. Van Laarhoven ve Pedrycz (1983), çelişkili karar kriterleri altındaki bir dizi alternatif arasından seçim yapmak için bulanık bir yöntem sunmuşlar ve böylece AHP yöntemine bulanık mantık yaklaşımının ilk uygulamasını gerçekleştirmişlerdir. Yazarlara göre gerçek hayatta daima karşımıza çelişkili karar kriterleri çıkmaktadır ve buna çözüm yöntemleri geliştirilmesi gerekmektedir.

Bundan sebeplerden dolayı çalışmada Türk marka patenti otomobil üretimi öncesinde potansiyel müşterilerin risk algısının ağırlıklarının bulunması Bulanık Analitik Hiyerarşi Prosesi (BAHP) yöntemi ile hesaplanmıştır.

\section{Uygulama (Application)}

Üretimi gerçekleşmemiş bir ürün için algı, birçok risk unsuru içerdiğinden bu çalışmada risk algısı üzerinden değerlendirme yapılmıştır. Uygulamada Türk marka patentli otomobil üretimi öncesinde potansiyel müşteriler için risk algısı araştırılmıştır.

Uygulamada; literatürde tanımlanan 6 risk algısının boyutlarının her birinin tanımları potansiyel tüketicilere verilmiş ve bu tanımlar dikkate alındığında yerli otomobil düşünülerek risk algılarının birbiriyle karşılaştırılması istenmiştir. Bu kıyaslama neticesinde katılımcılar risk algılarına kendi algıları ile puan vermişlerdir. Böylece elde edilen ikili karşılaştırma matrisleri geometrik ortalamaları alınarak tek ikili karşılaştırma matrisine dönüştürülmüştür. Bulanık AHP prosedürüne uygun risk ağırlıkları elde edilmiştir. Bu çalışmada, AHP’ye bulanık bir yaklaşım olan Chang' in (1996) yöntemi kullanılmıştır. Literatürde sıkça kullanılan bir yöntem olduğunda bu makalede yöntemin detayları verilmemiştir. Chang (1996), Toklu ve Uygun (2019) makalelerinde işlem ayrıntıları incelenebilir.

AHP, objektif ve sübjektif tüm ölçütleri ikili karşılaştırma yaparak ölçen ve bu ölçütlerin birbirlerine göre önceliklerini bularak önem sıralarını belirleyen bir karar verme tekniğidir (Byun, 2001). Her bir faktör temelinde alternatiflerin değerlendirilmesi ve faktörlerin kendi aralarındaki önem derecelerinin belirlenmesi için ikili karşılaş̧ırma karar matrisleri oluşturulur (Keçek ve ark.,2010). Bu matrislerin oluşturulmasında Saaty (1980) tarafindan önerilen 1-9 önem skalası kullanılmıştır (Tablo 1).

Karar vericiler ölçekteki ifadelerden, karşılaştırma yapılan iki faktör hakkında fikirlerini yansıtanını seçer ve hesaplamada bu ifadenin karşıllğı olan sayısal değer (Tablo 1) kullanılır (Keçek vd., 2010).

Tablo 1. Önem skalası (Kaynak: Saaty, 1980)

\begin{tabular}{|c|l|l|}
\hline Değer & Tanım & Açılklama \\
\hline 1 & Eşit önemli & İki seçenek eşit derecede öneme sahip \\
\hline 3 & Biraz önemli & Ölçütlerden biri diğerine göre biraz önemli \\
\hline 5 & Fazla önemli & Ölçütlerden biri diğerine göre oldukça önemli \\
\hline 7 & Çok fazla önemli & Bir ölçüt diğerine göre üstün sayılmıstır. \\
\hline 9 & Aşırı derece önemli & Bir ölçüt diğerinden üstün olduğunu gösteren kanıt çok büyük \\
\hline 2.4 .6 .8 & Ara değerler & $\begin{array}{l}\text { Uzlaşma gerektiğinde kullanılmak üzere iki ardışı yarg1 } \\
\text { arasındaki değerler }\end{array}$ \\
\hline
\end{tabular}

TMPO için risk algısını ölçmek üzere katılımcıların literatürde tanımlanan 6 risk algısının birbiriyle kıyasladığı veriler önem skalasına (Tablo 1) uygun olarak ikili karşılaştırma matrisine (Tablo 2) aktarılmıştır. Risk algı faktörleri ikili karşılaştırma matrisleri elde edilmiştir. 
Tablo 2. Risk Alg1 Faktörleri İkili Karşılaştırma Matrisi

\begin{tabular}{|c|c|c|c|c|c|c|}
\hline & Finansal & Psikolojik & Fiziksel & Fonksiyonel & Sosyal & Zaman \\
\hline Finansal & 1 & 0,2 & 1 & 0,142857143 & 0,1428571 & 0,1111111 \\
\hline Psikolojik & 5 & 1 & 0,3333333 & 1 & 3 & 0,3333333 \\
\hline Fiziksel & 1 & 3 & 1 & 3 & 5 & 0,3333333 \\
\hline Fonksiyonel & 7 & 1 & 0,3333333 & 1 & 3 & 0,2 \\
\hline Sosyal & 7 & 0,3333333 & 0,2 & 0,333333333 & 1 & 0,1428571 \\
\hline Zaman & 9 & 3 & 3 & 5 & 7 & 1 \\
\hline
\end{tabular}

Önem dağılımlarını belirlemek için, karşılaştırma matrisinden hareketle N matrisi oluşturulur (Tablo 3). N matrisinin satır değerlerinin aritmetik ortalamasının alınması (Denklem 2) ile W ağırlık matrisi (Tablo 3) elde edilir.

$$
W_{i}=\frac{\sum_{j=1}^{n} N_{i j}}{n}
$$

Tablo 3. N Matrisi ve Wi Ağırlık Matrisi

\begin{tabular}{|c|c|c|c|c|c|c|}
\hline & Finansal & Psikolojik & Fiziksel & Fonksiyonel & Sosyal & Zaman \\
\hline Finansal & 0,0333333 & 0,0234375 & 0,1704545 & 0,013636364 & 0,0074627 & 0,0523952 \\
\hline Psikolojik & 0,1666667 & 0,1171875 & 0,0568182 & 0,095454545 & 0,1567164 & 0,1571856 \\
\hline Fiziksel & 0,0333333 & 0,3515625 & 0,1704545 & 0,286363636 & 0,261194 & 0,1571856 \\
\hline Fonksiyonel & 0,2333333 & 0,1171875 & 0,0568182 & 0,095454545 & 0,1567164 & 0,0943114 \\
\hline Sosyal & 0,2333333 & 0,0390625 & 0,0340909 & 0,031818182 & 0,0522388 & 0,0673653 \\
\hline Zaman & 0,3 & 0,3515625 & 0,5113636 & 0,477272727 & 0,3656716 & 0,4715569 \\
\hline
\end{tabular}

\begin{tabular}{|c|}
\hline $\mathrm{Wi}$ \\
\hline 0,05012 \\
\hline 0,125005 \\
\hline 0,210016 \\
\hline 0,125637 \\
\hline 0,076318 \\
\hline 0,412905 \\
\hline
\end{tabular}

AHP yöntemi bu karşılaştırmalardaki tutarlılığın ölçülebilmesi önerir. Özyörük vd. e göre (2014:8) tutarlılık, "ölçütlerin ya da alternatiflerin ikili karşılaştırmasının belirlenmesinde kararın uyumluluk göstermesidir."

Faktörler arasında yapılan birebir karşılaştırmaların tutarlılığın test edilebilmesi tutarlılık oranı (CR) ile sağlanır. Tutarlılık oranı Denklem 3'de görüldüğü gibidir.

$$
C R=\frac{C I}{R I}
$$

Tutarlılık oranı hesap edilirken öncelikle risk algı faktörleri karşılaştırma matrisi ile W matrisinin çarpımından $\mathrm{N}_{\max }$ matrisi ve matris değerleri toplamında $\mathrm{N}_{\max }$ değeri elde edilir (Tablo 4).

\begin{tabular}{|c|c|c|}
\hline Finansal & 0,359866 & \\
\hline Psikolojik & 0,937836 & \\
\hline Fiziksel & 1,531286 & \\
\hline Fonksiyonel & 0,983022 & \\
\hline Sosyal & 0,611694 & \\
\hline \multirow[t]{2}{*}{ Zaman } & 3,031457 & \\
\hline & 7,455161 & Nmax \\
\hline
\end{tabular}

Tablo 4. $\mathrm{N}_{\max }$ Matrisi ve $\mathrm{N}_{\max }$ Değeri 
Denklem 4'de görüldüğü gibi tutarlılık göstergesi (CI) değeri bulunur.

$$
C I=\frac{\mathrm{N}_{\max }-n}{n-1}
$$

Rassal gösterge olan RI, n değerine göre belirlenir.

Örnek anket için tutarlılık oranı 0,09 olarak bulunmuştur. Tutarlılık oranı (CR) nın \%10 un altında olması tutarlı olduğunu göstermektedir. Tüm matrislerin tutarll1ık analizleri yapılmıştır.

Uygulamada 5 kademeli (çok önemli, önemli, orta, az önemli, eşit) tanımlanan önem derecesi Tablo 5 'te görüldüğü gibi dilsel ifadeler üçgensel bulanık sayılarla ifade edilmiştir. Tutarlılık analizinden geçen matris değerleri üçgensel bulanık sayılarla ifade edilmişlerdir. Özetle dilsel ifadeler üçgensel bulanık sayılarla ifade edilmesi işlemi gerçekleştirilmiştir.

Tablo 5. Dilsel ifadelerin üçgensel bulanık sayılarla ifadesi

\begin{tabular}{|l|c|c|c|}
\hline DILSEL İFADE & $\begin{array}{c}\text { ÖNEM } \\
\text { DERECESİ }\end{array}$ & $\begin{array}{c}\text { BULANIK ÖNEM } \\
\text { DERECESİ }\end{array}$ & $\begin{array}{c}\text { BULANIK ÖNEM } \\
\text { DERECESI EȘLENIĞİ }\end{array}$ \\
\hline EŞiT & 1 & $(1,1,1)$ & $(1,1,1)$ \\
\hline AZ ÖNEMLİ & 3 & $(1,3,5)$ & $(1 / 5,1 / 3,1)$ \\
\hline ORTA & 5 & $(3,5,7)$ & $(1 / 7,1 / 5,1 / 3)$ \\
\hline ÖNEMLİ & 7 & $(5,7,9)$ & $(1 / 9,1 / 7,1 / 5)$ \\
\hline ÇOK ÖNEMLİ & 9 & $(7,9,9)$ & $(1 / 9,1 / 9,1 / 7)$ \\
\hline
\end{tabular}

Tablo 2'de yer alan risk algı faktörleri ikili karşılaştırma matrisi, Tablo 5'deki dilsel ifadelerin önem dereceleri dönüşümüyle bulanık risk algı faktörleri ikili karşılaştırma matrisi (Tablo 6) elde edilmiştir.

Tablo 6. Bulanık Risk Algı Faktörleri İkili Karşılaştırma Matrisi

\begin{tabular}{|c|c|c|c|c|c|c|c|c|c|c|c|c|c|c|c|c|c|c|c|}
\hline & \multicolumn{4}{|c|}{ Finansal } & \multicolumn{3}{|c|}{ Psikolojik } & \multicolumn{3}{c|}{ Fiziksel } & \multicolumn{3}{c|}{ Fonksiyonel } & \multicolumn{3}{c|}{ Sosyal } & \multicolumn{3}{c|}{ Zaman } \\
\hline & $\mathrm{I}$ & $\mathrm{m}$ & $\mathrm{u}$ & $\mathrm{I}$ & $\mathrm{m}$ & $\mathrm{U}$ & $\mathrm{I}$ & $\mathrm{m}$ & $\mathrm{u}$ & $\mathrm{L}$ & $\mathrm{m}$ & $\mathrm{U}$ & $\mathrm{I}$ & $\mathrm{m}$ & $\mathrm{U}$ & $\mathrm{I}$ & $\mathrm{m}$ & $\mathrm{u}$ \\
\hline Finansal & 1 & 1 & 1 & 0,1 & 0,2 & 0,3 & 1 & 1 & 1 & 0,1 & 0,1 & 0,1 & 0,1 & 0,1 & 0,1 & 0,1 & 0,1 & 0,1 \\
\hline Psikolojik & 3 & 5 & 7 & 1 & 1 & 1 & 0,2 & 0,3 & 0,3 & 1 & 1 & 1 & 1 & 3 & 3 & 0,2 & 0,2 & 0,2 \\
\hline Fiziksel & 1 & 1 & 1 & 1 & 3 & 5 & 1 & 1 & 1 & 1 & 3 & 3 & 3 & 5 & 5 & 0,2 & 0,2 & 0,2 \\
\hline Fonksiyonel & 5 & 7 & 9 & 1 & 1 & 1 & 0,2 & 0,3 & 0,3 & 1 & 1 & 1 & 1 & 3 & 3 & 0,1 & 0,1 & 0,1 \\
\hline Sosyal & 5 & 7 & 9 & 0,2 & 0,3 & 1 & 0,1 & 0,2 & 0,2 & 0,2 & 0,3 & 0,3 & 1 & 1 & 1 & 0,1 & 0,1 & 0,1 \\
\hline Zaman & 7 & 9 & 9 & 1 & 3 & 5 & 1 & 3 & 3 & 3 & 5 & 5 & 5 & 7 & 7 & 1 & 1 & 1 \\
\hline
\end{tabular}

Tüm katılımcıların verdiği bilgilerle oluşturulan bulanık risk algı faktörleri ikili karşılaştırma matrisleri geometrik ortalama alınarak tek matrise dönüştürülmüştür (Tablo 7).

Geometrik ortalaması alınan bulanık matrisin (Tablo 7) toplamları alınarak Toplam 1-m-u matrisi oluşur (Tablo 8). 
International Journal of Scientific and Technological Research

ISSN 2422-8702 (Online), DOI: 10.7176/JSTR/5-3-22

Vol.5, No.3, 2019

Tablo 7. Bulanık Risk Algı Faktörleri İkili Karşılaştırma Geometrik Ortalama Matrisi

\begin{tabular}{|c|c|c|c|c|c|c|c|c|c|c|c|c|c|c|c|c|c|c|}
\hline & \multicolumn{3}{|c|}{ Finansal } & \multicolumn{3}{|c|}{ Psikolojik } & \multicolumn{3}{|c|}{ Fiziksel } & \multicolumn{3}{|c|}{ Fonksiyonel } & \multicolumn{3}{|c|}{ Sosyal } & \multicolumn{3}{|c|}{ Zaman } \\
\hline & I & $\mathrm{m}$ & u & I & $\mathrm{m}$ & u & 1 & $\mathrm{~m}$ & u & I & $\mathrm{m}$ & $\mathrm{u}$ & 1 & $\mathrm{~m}$ & u & I & $\mathrm{m}$ & u \\
\hline Finansal & 1 & 1 & 1 & 1,046 & 1,467 & 2,116 & 0,734 & 0,94 & 0,94 & 0,616 & 0,914 & 0,914 & 0,5 & 0,859 & 0,859 & 0,734 & 0,734 & 0,734 \\
\hline Psikolojik & 0,473 & 0,681 & 0,956 & 1 & 1 & 1 & 0,553 & 0,925 & 0,925 & 0,647 & 1 & 1 & 0,789 & 1,119 & 1,119 & 0,612 & 0,612 & 0,612 \\
\hline Fiziksel & 0,831 & 1,064 & 1,363 & 0,602 & 1,082 & 1,808 & 1 & 1 & 1 & 0,637 & 1,052 & 1,052 & 0,674 & 1,1 & 1,1 & 0,821 & 0,821 & 0,821 \\
\hline Fonksiyonel & 0,746 & 1,094 & 1,623 & 0,647 & 1 & 1,545 & 0,633 & 0,951 & 0,951 & 1 & 1 & 1 & 0,776 & 1,246 & 1,246 & 0,538 & 0,538 & 0,538 \\
\hline Sosyal & 0,678 & 1,164 & 2,001 & 0,701 & 0,894 & 1,267 & 0,569 & 0,909 & 0,909 & 0,562 & 0,803 & 0,803 & 1 & 1 & 1 & 0,616 & 0,616 & 0,616 \\
\hline Zaman & 0,659 & 0,929 & 1,363 & 0,776 & 1,064 & 1,633 & 0,609 & 0,849 & 0,849 & 0,647 & 1,041 & 1,041 & 0,644 & 0,989 & 0,989 & 1 & 1 & 1 \\
\hline
\end{tabular}

Tablo 8. Bulanık Risk Algı Faktörleri İkili Karşılaştırma Geometrik Ortalama Matrisi

\begin{tabular}{|c|c|c|c|}
\hline & TOPLAM L & TOPLAM M & TOPLAM U \\
\hline Finansal & 4,629006 & 5,914103 & 6,563068 \\
\hline Psikolojik & 4,07429 & 5,33755 & 5,61221 \\
\hline Fiziksel & 4,564008 & 6,117376 & 7,143695 \\
\hline Fonksiyonel & 4,340271 & 5,82854 & 6,90217 \\
\hline Sosyal & 4,124981 & 5,385629 & 6,596335 \\
\hline Zaman & 4,335277 & 5,87242 & 6,874678 \\
\hline TOPLAM & 26,06783 & 34,45562 & 39,69216 \\
\hline $\begin{array}{c}\text { TERS } \\
\text { TOPLAM }\end{array}$ & 0,025194 & 0,029023 & 0,038361 \\
\hline
\end{tabular}

Bulanık sentetik derece değeri (i ölçütüne ait) Denklem 5 de görüldüğü gibi hesap edilir.

$$
S_{i}=\sum_{j=1}^{m} \mathrm{M}_{g i}^{j} \otimes\left|\sum_{i=1}^{n} \sum_{j=1}^{m} M_{g i}^{j}\right|^{-1}
$$

$\mathrm{l}_{\mathrm{i}}, \mathrm{m}_{\mathrm{i}}, \mathrm{u}_{\mathrm{i}}$ üçgensel bir bulanık sayı olmak üzere;

$$
\begin{aligned}
& \sum_{j=1}^{m} M_{g i}^{j}=\left(\sum_{j=1}^{m} l_{j}, \sum_{j=1}^{m} m_{j}, \sum_{j=1}^{m} u_{j}\right) \\
& {\left[\sum_{i=1}^{n} \sum_{j=1}^{m} M_{g i}^{j}\right]^{-1}=\left(\frac{1}{\sum_{j=1}^{m} u_{j}}, \frac{1}{\sum_{j=1}^{m} m_{j}}, \frac{1}{\sum_{j=1}^{m} l_{j}}\right)}
\end{aligned}
$$

bulunur. Denklem 5,6,7 eşitliği kullanılarak S Matrisi (Tablo 9) hesaplanır.

Tablo 9. Bulanık Risk Alg1 Faktörleri S Matrisi

\begin{tabular}{|c|c|c|c|}
\hline & $\mathrm{L}$ & $\mathrm{M}$ & $\mathrm{U}$ \\
\hline Finansal & 0,116623 & 0,171644 & 0,251769 \\
\hline Psikolojik & 0,102647 & 0,154911 & 0,215293 \\
\hline Fiziksel & 0,114985 & 0,177544 & 0,274043 \\
\hline Fonksiyonel & 0,109348 & 0,169161 & 0,264777 \\
\hline Sosyal & 0,103924 & 0,156306 & 0,253045 \\
\hline Zaman & 0,109223 & 0,170434 & 0,263723 \\
\hline
\end{tabular}

207 | P a g e

www.iiste.org 
$\mathrm{M}_{1}=\left(l_{1}, m_{1}, u_{1}\right)$ ve $\mathrm{M}_{2}=\left(l_{2}, m_{2}, u_{2}\right)$ üçgensel bulanık sayıları için, $\mathrm{V}\left(\mathrm{M}_{1} \geq \mathrm{M}_{2}\right)$ ve $\mathrm{V}\left(\mathrm{M}_{2} \geq \mathrm{M}_{1}\right)$ değerlerinin her ikisi de hesaplanarak $M_{1}$ ve $M_{2}$ sayıları karşılaştırılmaktadır. Bunun için, $V\left(M_{2} \geq M_{1}\right)$ ifadesi $M_{2} \geq M_{1}$ olabilirliğini belirtmek üzere,

$$
V\left(M_{2} \geq M_{1}\right)= \begin{cases}1 & , m_{2} \geq m_{1} \\ 0 & , l_{1} \geq u_{2} \\ \frac{\left(l_{1}-u_{1}\right)}{(m-u)-(m-l)} & , d d\end{cases}
$$

dir. S matrisinde denklem 8 kullanılarak bulanık risk algı faktörleri ikili karşılaştırma ağırlık matrisi elde edilir (Tablo 10).

Tablo 10. Bulanık Risk Algı Faktörleri İkili Karşılaştırma Ağırlık Matrisi

\begin{tabular}{|c|c|c|c|c|c|c|}
\hline & Finansal & Psikolojik & Fiziksel & Fonksiyonel & Sosyal & Zaman \\
\hline Finansal & $\mathrm{X}$ & 1 & 0,958653 & 1 & 1 & 1 \\
\hline Psikolojik & 0,855002 & $\mathrm{X}$ & 0,815904 & 0,88144258 & 0,987626 & 0,872333 \\
\hline Fiziksel & 1 & 1 & $\mathrm{X}$ & 1 & 1 & 1 \\
\hline Fonksiyonel & 0,983515 & 1 & 1 & $\mathrm{X}$ & 1 & 0,991879 \\
\hline Sosyal & 0,898934 & 1 & 0,866681 & 0,91788938 & $\mathrm{X}$ & 0,910554 \\
\hline Zaman & 0,991843 & 1 & 0,954383 & 1 & 1 & $\mathrm{X}$ \\
\hline
\end{tabular}

\begin{tabular}{|l|l|}
\hline \multicolumn{1}{|c|}{ MIN } & \multicolumn{1}{c|}{ Wi } \\
\hline 0,958653 & 0,171828 \\
\hline 0,815904 & 0,146242 \\
\hline 1 & 0,179239 \\
\hline 0,983515 & 0,176284 \\
\hline 0,866681 & 0,155343 \\
\hline 0,954383 & 0,171063 \\
\hline 5,579135 & \multicolumn{1}{|c|}{1} \\
\hline
\end{tabular}

Sonuç olarak; katılımcı verilerinden hareketle risk algı faktörlerinin kendi aralarındaki önem derecelerinin belirlenmesi için ikili karşılaştırma karar matrisleri oluşturulmuştur. Böylece sözel ifadeler sayısal verilere dönüştürülmüş, BAHP ile ağırlıkları bulunmuştur (Tablo 11).

Tablo.11. Potansiyel Müşteri açısından Risk Algı Ağırlıkları

\begin{tabular}{|l|l|}
\hline RiSK ALGI TANIMI & BAHP Wi \\
\hline Finansal Risk & 0,171828 \\
\hline Psikolojik Risk & 0,146242 \\
\hline Fiziksel Risk & 0,179239 \\
\hline Fonksiyonel Risk & 0,176284 \\
\hline Sosyal Risk & 0,155343 \\
\hline Zaman Riski & 0,171063 \\
\hline & 1 \\
\hline
\end{tabular}

Tüketici risk algısının ölçülmesi ve analizi amacıyla hazırlanan anket 25 kişiye uygulanmıştır. Örneklem grubun eğitim ve gelir seviyeleri Tablo 12 de verilmiştir.

Örneklem 11 kadın 14 erkekten oluşmaktadır. Gelir düzeyi 0-2000 TL arası 1, 2000-4000 TL arası 3, 4000-6000 TL arası 8, 6000 TL üstü 13 kişi anket değerlendirmeye katılmıştır. Eğitim seviyesi dikkate alındığında 5 kişi lise, 12 kişi üniversite, 1 kişi yüksek lisans, 7 kişi doktora mezunudur. Araştırma konusu gereği katılımcılar daha çok eğitim düzeyi ve gelir düzeyi yüksek kişilerden seçilmiştir. 
Tablo 12. Katılımcı eğitim ve gelir durumu

\begin{tabular}{|c|c|c|c|c|c|c|c|c|c|}
\hline & \multicolumn{4}{|c|}{ KADIN } & \multicolumn{4}{|c|}{ ERKEK } & \multirow[b]{2}{*}{ 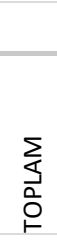 } \\
\hline & 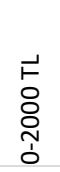 & 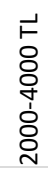 & 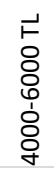 & 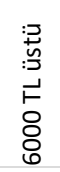 & 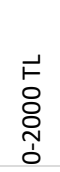 & $\begin{array}{l}\vec{F} \\
8 \\
8 \\
+ \\
\dot{1} \\
\stackrel{ }{0}\end{array}$ & 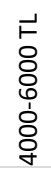 & 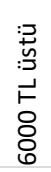 & \\
\hline Lise & & & & 1 & & & & 4 & 5 \\
\hline Üniversite & & & 4 & 1 & 1 & 2 & 1 & 3 & 12 \\
\hline $\begin{array}{l}\text { Yüksek } \\
\text { lisans }\end{array}$ & & & 1 & & & & & & 1 \\
\hline Doktora & & 1 & 1 & 2 & & & 1 & 2 & 7 \\
\hline TOPLAM & 0 & 1 & 6 & 4 & 1 & 2 & 2 & 9 & 25 \\
\hline
\end{tabular}

Üretimi gerçekleşmemiş bir ürünün potansiyel müşterilerinin risk algısını ölçmeye yönelik bir araştırma yapıldığından; katılımcıların bu ürün (TPMO) hakkında bilgi seviyelerini ölçmeye yönelik sorular da sorulmuştur. Bu sorulardan elde edilen sonuç; Örneklemde yer alan kişilerin bilgi seviyelerinin homojen olduğu söylenemez. Aynı zamanda bu üretimi destekledikleri söylenebilir.

Katılımcılara yerli otomobil üretiminin Türkiye için stratejik önemi sorulmuş; \% 88 (22 kişi) çok stratejik olduğunu belirtmiştir. "Yerli otomobil üretildiğinde satın almayı düşünür müsünüz" sorusuna katılımcıların verdiği cevap; \% 40 (10 kişi) ile "Mutlaka yerli otomobili alırım" olmuştur.

\section{Sonuç (Conclusion)}

Otomobil gibi toplumda statü göstergesi olarak kabul edilen ürünlerin pazara sunumu öncesinde algı analizinin yapılmasının pek çok fayda sağlayacaktır. Üreticinin, bu analizler sonucunda müşterinin yanlış algılarını doğru bilgiler ile dönüştürme stratejileri belirlemesine katkı sağlayacağı söylenebilir.

Bu çalışmada yerli otomobil için potansiyel müşterilerin risk algısı araştırılmış ve analiz edilmiştir. Uygulama otomobil alımı üzerine kurgulanan risk algısı araştırması olduğundan katılımcılar eğitim ve gelir düzeyi yüksek olanlardan seçilmiştir.

Potansiyel müşseriler yerli otomobil için riskleri sıralarken net bir ayırım yapamamıştır. Buna rağmen en yüksek gördüğü risk; Ürünün kullanımı esnasında kullanıcıya ve başkalarına zarar vermesi riski olan fiziksel risktir. Değerler birbirine çok yakın olmakla birlikte ikinci sırayı "Ürünün istenilen performansı verememesi riski” olan fonksiyonel risk yer almaktadır. "Ürüne verilen paranın boşa gitmesi riski" olan finansal risk ise üçüncü sırada yer almaktadır. Bununla birlikte, sosyal çevrede kabul görmeme ve egoya zarar verme olarak özetlenebilen sosyal ve psikolojik riskler, tam da ihmal edilmemekle birlikte değerlendirmede en düşük ağırlık puanlarını almıştır. Özetle yerli otomobil için potansiyel müşterilerin risk algısı, "kullanım sırasında oluşabilecek zarar, ürünün düşük performansı ve dolayısıyla parasının boşa gitmesi” olmak üzere bu üç unsur üzerine kurulmuştur. Bu algının neticesinde de örneklemin \% 401 yerli otomobili satın alacağını bildirmektedir.

Sonuç olarak, risk algısı yanında potansiyel müşterilerin algı analizleri yapılmalı, algı ile gerçeklik arasında fark tespit edilirse ya da belirlenen algı ile hedeflenen algı farklı ise etik değerler 1şığında olumlu algı yönetimi stratejileri belirlenmelidir. $\mathrm{Bu}$ stratejileri belirlerken doğru bilginin, etik değerlerin, güvenin müşteri algısı üzerindeki pozitif etkisi unutulmamalıdır.

Türkiye'deki araba sayısı dikkate alınarak hesaplanan örneklem sayısı ile bu analizlerin yapılması faydalı olacaktır.

\section{Kaynakça (Reference)}

Aktan, M. (2013) Kamuoyunun Yerli Otomobil Projesini Algısı", Marmara Üniversitesi e-Dergisi, Cilt 10, Say1 39 . 
Byun D.H. (2001) The AHP approach for selecting an automobile purchase model. Information \& Management, 38, 289-297.

Cengiz Toklu, M., Uygun, Ö. (2018) "Location Selection for Wind Plant using AHP and Axiomatic Design in Fuzzy Environment", Periodicals of Engineering and Natural Scinces, Vol.6, No.2, pp. 120-128

Chang, D. Y. (1996)“Applications of the extent analysis method on fuzzy AHP,” Eur. J. Oper. Res., vol. 95, no. 3, pp. 649-655.

Cüceloğlu, D. (2007). Yeniden İnsan İnsana, 37.Baskı, Remzi Kitabevi, İstanbul.

Cüceloğlu, D. (1999). İnsan ve Davranışı, 7. Baskı, Remzi Kitabevi, İstanbul.

Demir, M.Ö. (2011). Risk Algısının Marka Sadakatine Etkisi: Cep Telefonları Kategorisinde Bir Uygulama. Ege Akademik Bakış, 11(2), 267-276.

Demir, Ş.Ş., Kozak, M. (2013). Tüketici Davranışları, Detay Yayıncılık, Ankara.

Doğar, N. (2016). Stratejik Yönetim Enstrümanı Olarak Algı ve Arnavutluk'ta Türkiye Algısı, Nobel Bilimsel Eserler, Ankara.

Eren, E. (2001) Yönetim ve Organizasyon, Beta Yayınc1lık, İstanbul.

Erişti, S.D., Uluuysal, B., Dindar, M. (2013). Görsel Algı Kuramlarına Dayalı Etkileşimli Bir Öğretim Ortamı Tasarımı ve Ortama İlişkin Öğrenci Görüşleri”, Anadolu Journal of Educational Sciences International, $3(1)$.

Kaplan, L.B., Szybillo, G.J. \& Jacoby, Jacob. (1974). Compenents of Perceived Risk in Product Purchase. Journal of Applied Psychology, 59(3), 287-291.

Karatop, B. (2015) Yerli Otomotiv Yatırımında Odak Strateji Karar Modeli: Bulanık AHP Uygulaması”, Doğu Kütüphanesi, İstanbul.

Keçek, G., Yıldırım, E. (2010) Kurumsal Kaynak Planlama (ERP) Sistemini Analitik Hiyerarşik Proses (AHP) ile Seçimi: Otomotiv Sektöründe bir Uygulama, Süleyman Demirel Üniversitesi, İktisadi ve İdari Bilimler Fakültesi Dergisi, 15(1), 193-211.

Koç, E. (2015). Tüketici Davranışı ve Pazarlama Stratejileri: Global ve Yerel Yaklaşım, 6.Baskı, Seçkin Yayıncılık, Ankara.

Kotler, P. (2001). A framework for marketing management. Upper Saddle River, NJ: Prentice Hall.

Kubat, C. (2012) MATLAB Yapay Zeka ve Mühendislik Uygulamaları, Beşiz yayınları, Sakarya.

Kubat, C. (2015) MATLAB Yapay Zeka ve Mühendislik Uygulamaları, Abaküs yayınları, İstanbul.

Özer, M.A. (2012) Bir Modern Yönetim Tekniği Olarak Algılama Yönetimi ve İç Güvenlik Hizmetleri, Karadeniz Araştırmaları, Sayı 33, 147-180.

Özsalmanlı, A., Pank, Ç. (2013) Kamu Yönetiminde Etik Açısından Algılama Yönetimi ve Önemi, Hukuk ve İktisat Araştırmaları Dergisi Cilt 5, No 2.

Öztemel, E. (2009) Endüstri Mühendisliğine Giriş, Editör: Öztemel, E., Papatya Yayıncılık Eğitim. 
Özyörük B, Şirin Y, Yoksulabakan, T., Şanver, M., Saraç, M.A. (2014) Performans Ölçümünde Dengelenmiş Skor Kart Ve Analitik Hiyerarşi Prosesi Entegrasyonu, Tübav, Cilt:2, Sayı:1, ss:7-28.

Pickens, J. (2005). “Attitudes and Perceptions", Organizational Behavior in Health Care, Ed. Nancy Borkowski, 2nd Edition, Massachusetts, USA.

Ronnie L M. Johansson-Ning Xiong (2006). Perception Management: An Emerging Concept for Information Fusion, http://www.csc.kth.se/ ronniej/pubs/perception_management.pdf (Erişim Tarihi: Mayis.2016).

Saaty, T.L. (1972) An Eigenvalue Allocation Model for Prioritization and Planning; Working Paper; University of Pennsylvania, Energy Management and Policy Center: Philadelphia, PA, USA.

Saaty, T.L. (1977) A scaling method for priorities in hierarchical structures. J. Math. Psychol. 15, 234-281.

Saaty, T.L. (1980) The Analytic Hierarchy Process. McGraw-Hill, New York, 1980.

Schiffman, L.G., Kanuk, L.L. (2000) Costumer Behavior, NJ: Prentice Hall.

Snoj, B., Korda, A.P. \& Mumel, D. (2004). The Relationships Among Perceived Quality, Perceived Risk and Perceived Product Value. Journal of Product\&Brand Management, 13(3), 156-167.

Stefanoiu, D.; Borne, P.; Popescu, D.; Filip, F.G.; El Kamel, A. (2014) Optimization in Engineering Sciences. Approximate and Metaheuristic Methods; John Wiley \& Sons: Hoboken, NJ, USA.

Stone, R.N. \& Gronhaug, K. (1993). Perceived Risk: Further Considerations for the Marketing Discipline. European Journal of Marketing, 27(3), 39-50.

Turskis, Z.; Urbonas, K.; Daniūnas, A. (2019) A Hybrid Fuzzy Group Multi-Criteria Assessment of Structural Solutions of the Symmetric Frame Alternatives. Symmetry, 11, 261.

Van Laarhoven, P.J.M.; Pedrycz, W. (1983) A fuzzy extension of Saaty's priority theory. Fuzzy Sets Syst. $11,229-241$.

Zadeh, L.A. (1965). Fuzzy Sets, Information and Control, 8, 338-353, 